\title{
AGRICULTURA MODELO: CAPACITAÇÃO DE JOVENS HABITANTES DA ZONA RURAL DA APA DE BOTUCATU EM AGRICULTURA SUSTENTÁVEL
}

\author{
Marísia Cristina da Silva ${ }^{1}$
}

\author{
Luiz César Ribas ${ }^{2}$
}

\section{Bernardo Tomchinsky ${ }^{3}$}

RESUMO: O êxodo rural nada mais é que a migração do homem do campo para cidades remanescentes ou até mesmo para grandes centros. Assim, o resultado desse fenômeno é a deterioração social e ambiental do meio rural. O rural, sem condições de trabalho digno, sem perspectiva de vida no campo sai rumo a meio urbano em busca de condições melhor de vida e emprego. Isso decorrente da modernização da agricultura que faz com que o agricultor familiar não consiga se modernizar no mesmo ritmo. Daí então o desinteresse dos filhos desses agricultores em permanecer no campo e ter a minha vida com dificuldades dos pais. $O$ Projeto Agricultura Modelo: Capacitação de jovens habitantes da zona rural da APA de Botucatu buscou difundir conhecimentos, bem como prestar tecnologias adequadas para que o jovem morador da área rural da APA de Botucatu tivesse formas alternativas para se fixar no campo. Como isso, a aproximação desses jovens com o meio acadêmico se tornasse proveitosa para ambas as partes, possibilitando um intercâmbio de informações, identificação das problemáticas atuais do jovem no campo e a troca de experiências. Objetivou principalmente envolver e comprometer os (as) jovens agricultores (as) para que se fixem no campo, para que possam assim, contribuir para o processo de recuperação e gestão ambiental e, ao

\footnotetext{
${ }^{1}$ Engenheira Agrônoma, Doutoranda em Agronomia pelo Programa de Pós-Graduação Energia na Agricultura - Faculdade de Ciências Agronômicas - UNESP. E-mail: mcsilva@fca.unesp.br.

2 Engenheiro Florestal, Faculdade de Ciências Agronômicas - UNESP. Professor Assistente Doutor. E-mail: Icribas@fca.unesp.br.

${ }^{3}$ Engenheiro Agrônomo, Mestrando em Agronomia pelo Programa de Pós-Graduação Horticultura Faculdade de Ciências Agronômicas - UNESP. E-mail: Bernardo Tomchinsky <berinsky@uol.com.br>.
} 
mesmo tempo, para que possam diversificar suas rendas e fazer frente ativamente à contaminação dos recursos hídricos do Aqüífero Guarani nesta área de recarga; ajudando assim também a minimizar o fenômeno do êxodo rural.

Palavras-chave: Sustentabilidade, êxodo rural, Aquífero Guarani.

\section{INTRODUÇÃO}

O fenômeno do "êxodo rural" continua sendo um grande problema social, econômico e, mais recentemente, ambiental, para muitos municípios de vocação agropecuária. Isto porque o modelo econômico implantado no país favoreceu de sobremaneira os agricultores de médio e grande porte. Este fenômeno sempre esteve historicamente relacionado à queda da produtividade do solo em terras agrícolas, à falta de políticas públicas e ações de desenvolvimento das zonas rurais (infraestrutura, linhas de crédito, educação direcionada, centros de saúde, geração de emprego no meio rural, bem como o próprio surgimento de melhores oportunidades de trabalho nos centros urbanos, dentre outros aspectos).

O jovem morador da zona rural encontra-se especialmente atraído pela cidade e muito desinteressado pelas atividades do campo que muitas vezes são realizadas há várias gerações. De acordo com Champagne (1986), o principal motivo para a recusa desses jovens em sucederem os próprios pais é o modo de vida dos pais.

Com respeito à presença do jovem na área rural, Carneiro (2005) destaca que esta faixa demográfica é afetada drasticamente pela dinâmica de diluição das fronteiras presentes entre o espaço urbano e o espaço rural. Aponta ainda, o autor, como agravante, a intensificação da falta de perspectiva para o rural que sobrevive da agricultura.

Barreto \& Fontoura (2011) ressaltam que a modernização do campo e o êxodo rural estão intimamente ligados aos processos de urbanização recente, não apenas pela falta de perspectiva de subsistência das populações no campo e a busca de alternativa na cidade, mas pelo impulso da industrialização, que absorve certa parte da mão-de-obra excedente do meio rural. 
Porém, se faz necessária a preocupação tanto com as transformações e impactos no meio ambiente quanto com o estímulo ao desenvolvimento de um modelo econômico de desenvolvimento sustentável para os moradores da zona rural.

A busca por produzir alimentos, gerar renda minimamente satisfatória, reduzir ao máximo o impacto ambiental, praticar manejo conservacionista dos solos agrícolas, efetuar um planejamento agrícola em conformidade com a legislação ambiental, propiciar a conservação dos recursos naturais (sobretudo os hídricos e os florestais), além de efetuar a gestão ambiental dos resíduos agrícolas traduzem-se como objetivos efetivos destas preocupações ambientais.

Kozioski \& Ciocca (2000) afirmam que os sistemas intensivos de produção agrícola têm causado sérios danos ambientais caracterizados, por um lado, pelo rápido esgotamento de recursos naturais e, por outro, pela poluição e/ou contaminação devido à excessiva liberação de componentes residuais no meio ambiente.

Dentro deste escopo insere-se a região atendida pelo projeto: Área de Proteção Ambiental (APA) Corumbataí-Botucatu-Tejupá (perímetro Botucatu) ${ }^{4}$, a qual tem uma área aproximada de mais de 218.306,00 hectares e envolve 9 municípios ${ }^{5}$.

Essa APA foi criada fundamentalmente para proteger atributos ambientais tais como a Cuesta Basáltica, os remanescentes de vegetação de Cerrado e Mata Atlântica, bem como as áreas de recarga do Aquífero Guarani.

Nesta região, em se tratando do aspecto social, um dos fatores mais alarmantes tem sido justamente o êxodo rural majoritariamente da população jovem.

Pode-se dizer que os principais motivos desse problema social relacionam-se à baixa renda proporcionada pela atividade agrícola regional, à inadequada organização e administração rural e a pouca agregação de valor aos produtos agrícolas lá produzidos.

Dos municípios integrantes da APA de Botucatu, foram selecionados Botucatu (município sede do projeto), Torre de Pedra, Guareí e Angatuba (por apresentarem problemáticas sócio-ambientais mais representativas, bem como a relevância das

\footnotetext{
${ }^{4}$ Base legal para a criação da referida Unidade de Conservação: Decreto Estadual n. 20.960, de 08/06/1983; Deliberação CONSEMA no 142 de 12/12/1986, Lei Estadual n. 7.438 de 06/07/1991 e Resolução SMA s/n de 11 de março de 1987. (http://www.fflorestal.sp.gov.br/)

5 O conjunto destes municípios tem uma base econômica eminentemente agrícola (reflorestamento, pecuária e agricultura).
} 
atividades agrícolas e pastoris para os municípios em termos da contribuição sócioeconômica; em outras palavras, participação das atividades agrícolas e pastoris em termos de produção física, faturamento, empregabilidade, fixação do homem ao campo, dentre outros aspectos e em contraponto a outras atividades econômicas tais como reflorestamento, agroindústria, atividades comerciais, etc.).

O objetivo do Projeto Agricultura Modelo: Capacitação de jovens habitantes da zona rural da APA de Botucatu em agricultura sustentável; foi divulgar conhecimentos e técnicas, além de proporcionar a apropriação de tecnologias apropriadas de forma a criar alternativas para a fixação do jovem na área rural da APA de Botucatu ${ }^{6}$, bem como envolver e comprometer os (as) jovens agricultores (as) para que se fixem no campo, para que possam assim, contribuir para o processo de recuperação e gestão ambiental e, ao mesmo tempo, diversificar suas rendas e fazer frente ativamente à contaminação dos recursos hídricos do Aqüífero Guarani nesta área de recarga.

Pretendeu-se também, por intermédio da FCA e demais parceiros do projeto, contribuir para a conscientização ambiental dos jovens da área rural da APA de Botucatu e à formulação de materiais didáticos, bem como, a realização de cursos e atividades voltados para a sistematização das principais atividades agrícolas de propriedades rurais inseridas na referida APA, visando à produção rural sustentável, o respeito ao meio ambiente, à geração de fontes de renda fixa, bem como à educação de questões relacionadas à saúde e segurança do trabalho. Além disso, o projeto visou a aproximação do meio rural com o meio universitário, de maneira a possibilitar um maior intercâmbio de informações, identificação das problemáticas atuais do jovem no campo e a troca de experiências.

\section{DESENVOLVIMENTO}

O Projeto foi dividido em cinco etapas, denominadas Módulos, e realizado em períodos de férias escolares para garantir a freqüência dos jovens e máximas participações dos docentes, alunos de graduação e pós-graduação, bem como

\footnotetext{
${ }^{6}$ Para atender este objetivo principal pretendeu-se efetuar a capacitação de recursos humanos para dissipar as informações junto ao público primário de jovens da zona rural de quatro municípios da APA de Botucatu.
} 
funcionários da Universidade. Toda a infra-estrutura necessária para o desenvolvimento das atividades nas cinco etapas do Projeto foi disponibilizada pelas Faculdades de Ciências Agronômicas, Faculdade de Medicina Veterinária e Zootecnia e Instituto de Biociências de Botucatu.

\subsection{Estruturação dos 5 Módulos do Projeto}

A Coordenação Geral do Projeto Intervivência Universitária, financiado pelo Conselho Nacional de Desenvolvimento Científico e Tecnológico (CNPq), composta por: docentes, alunos de graduação e alunos de pós-graduação; iniciaram as atividades pertinentes ao Projeto no início do mês de janeiro de 2009, com reuniões periódicas com docentes, estudantes, profissionais e interessados.

Essas reuniões tinham por objetivo definir a seleção dos jovens participantes, o formato dos Módulos de ensino, bem como, estruturar a equipe que desenvolveria as atividades presentes no projeto:
a) Módulo 1 - Julho de 2009
b) Módulo 2 - Janeiro de 2010
c) Módulo 3 - Fevereiro de 2010
d) Módulos 4 e 5 - Julho de 2010

Para a realização dos Módulos do projeto, contou-se com apoio logístico da Faculdade de Ciências Agronômicas de Botucatu para receber os alunos, bem como a estrutura de hospedagem, alimentação e salas para ministrar os conteúdos programáticos.

O alojamento dos jovens, bem como a realização das refeições (café-da-manhã, almoço e jantar), nos cinco dias de aulas, deu-se em um prédio que a Faculdade de Ciências Agronômicas cede ao Serviço Nacional de Aprendizagem Rural (SENAR), para a realização do programa Jovem Aprendiz.

A equipe de monitores do Projeto contou com a assessoria integral dos bolsistas; que auxiliaram em todas as atividades propostas aos jovens, além de proporcionarem a 
estrutura necessária para o desenvolvimento de cada assunto; sendo este em sala de aula, laboratório ou a campo.

Para receber os jovens por cinco dias em julho de 2009; a Coordenação desenvolveu uma infra-estrutura que contou com alojamento masculino e feminino; refeitório, ônibus interno para o deslocamento ao local de aula, salas apropriadas para o desenvolvimento das atividades ao longo do dia e das atividades culturais no período da noite.

\subsubsection{Módulo 1}

Para a estruturação do Módulo que abordou o Tema "Saúde e Nutrição"; a Coordenação Geral primeiramente definiu os municípios que seriam contemplados com a participação do Projeto e em seguida realizou visitas a esses municípios para a seleção dos jovens e obtenção de informações necessárias ao desenvolvimento das atividades propostas ao referente Módulo.

Sendo assim; os jovens participantes foram selecionados levando em consideração:

a) Ter entre 15 e 18 anos;

b) Estar devidamente matriculado no ensino médio;

c) Apresentar bom desempenho escolar;

d) Ser morador de área rural ou ter algum contato com o mesmo.

Após a primeira visita aos municípios escolhidos para participar do Projeto; a Coordenação aguardou a indicação dos jovens que foi feita por escolas de cada município.

Também nesse período, a equipe de alunos e docentes dos cursos de Enfermagem, Nutrição, Agronomia e Engenharia Florestal; elaboraram material didáticopedagógico com linguagem simples, para fornecer aos alunos, durante as aulas na semana de realização do Módulo.

Porém; também se observou que havia necessidade de preparar aulas com linguagem acessível aos jovens, não desmerecendo os termos técnicos, mas que proporcionasse amplo entendimento em cada assunto abordado. Assim; a equipe de 
monitores contou com a assessoria pedagógica das Faculdades de Ciências Agronômicas e Medicina Veterinária e Zootecnia.

Com a orientação da Assessoria Pedagógica, as aulas teóricas foram ministradas dispondo as carteiras em forma de semicírculo, com o intuito de proporcionar um ambiente diferente do oferecido nas escolas aos alunos usualmente. Assim; pôde-se criar um clima em que todos, se aproximassem de forma participativa, bem como trocassem experiências vivenciadas no mundo acadêmico, pelos monitores, e no meio rural, pelos alunos.

Esse material didático-pedagógico (em forma de apostila) foi composto por capítulos referentes às frentes de aula oferecidas nos cinco Módulos de ensino, totalizando cinco apostilas. Para a finalização do material, o mesmo passou por revisão técnica e o mesmo foi submetido à publicação de obra volumada (05 volumes) para divulgação do trabalho desenvolvido pelo Projeto.

O Módulo 1 abordou os seguintes assuntos:

\section{_ Primeiros Socorros e Curativos}

_ Biologia e Identificação de Animais Peçonhentos e Prevenção Contra Acidentes

_ Treinamento e Educação no Setor de Tecnologia de Aplicação de Agrotóxicos

_ Introdução A Ergonomia e Segurança do Trabalho

_ Escravidão Branca: Mito ou Realidade muito próxima a nós? Legislação e Normas: Tópicos em Sustentabilidade

_ Nutrição: Alimentação Saudável para você e o Meio Ambiente

_ As Plantas Medicinais e a Sustentabilidade da APA de Botucatu

Vale ressaltar que as frentes de aula, em sua maioria, foram ministradas com partes teóricas e práticas para consolidar o aprendizado dos alunos e proporcionar uma forma diferenciada de aprender. Sempre que possível, as aulas iniciaram-se com a parte prática, seguida da teórica. Esse formato foi adotado sob a orientação da Assessoria Pedagógica da Faculdade. 


\subsubsection{Módulo 2}

Para a estruturação do Módulo 2 que abordou o Tema "Produção Agrícola"; a Coordenação Geral e seus colaboradores, contaram com a mesma logística utilizada para a realização do Módulo 1, com a Assessoria Pedagógica para a estruturação das aulas, com o apoio da Faculdade de Ciências Agronômicas para a utilização de suas dependências, bem como a utilização de áreas experimentais para as aulas a campo.

O Módulo 2 abordou os seguintes assuntos:

_ Conceitos Básicos de Fertilidade e Adubação do Solo

_ Máquinas para Preparo e Conservação de Solo

_ Produção de Hortaliças

_ Cultura do Milho

_ Cultura da Mandioca

_ Manejo Sustentável de um Pomar Doméstico

\subsubsection{Módulo 3}

Com a mesma estruturação e logística utilizada para os Módulos anteriores, realizou-se o Módulo 3 que abordou o Tema "Produção Animal". Porém, esse módulo foi realizado basicamente a campo, contando com visitas às fazendas da região e nos setores de produção animal da Faculdade de Medicina Veterinária e Zootecnia.

Com a mesma preocupação de utilizar linguagem fácil e acessível, além de oferecer aulas mais dinâmicas, todas as aulas do referido Módulo foram elaboradas com muito cuidado, pois o contato dos alunos com os animais deveria ser de forma segura além de não proporcionar estresse aos animais com a presença humana.

O Módulo 3 abordou os seguintes assuntos:

_ Conceitos Básicos sobre Forragicultura e Integração Lavoura-Pecuária-Floresta

_ Bovinocultura de Leite

_ Ovinocultura de Sustentabilidade 
_ Conceitos Básicos de Piscicultura

_ Apicultura - A Arte de Criar Abelhas

_Produção de Suínos

_ Tecnologia do Leite

_ Os Animais Selvagens e a Propriedade Rural

\subsubsection{Módulo 4}

O Módulo 4 teve como tema "Ecologia e Utilização dos Recursos Naturais" e realizou-se com a predominância de aulas teóricas-práticas com visitas às fazendas e propriedades que apresentam produções agroecológicas bem como uso de energias alternativas. Essas visitas objetivaram apresentar propriedades com métodos alternativos comparados com os convencionais, método predominantemente conhecido pelos jovens.

O Módulo 4 abordou os seguintes assuntos:

_ Terra: Planeta Água

_ Cuesta de Botucatu: Sua Paisagem, Florestas e Pessoas

_ Manejo de Resíduos: Destinação Correta para um Ambiente Saudável

_ Uso Racional da Energia no Meio Rural: Fontes de Energia Renovável

_ Manejo Ecológico do Solo e Práticas Conservacionistas

_ Agroecologia

\subsubsection{Módulo 5}

Empreendedorismo e Gestão da Propriedade Rural foi o tema trabalhado no Módulo 5, que ofereceu mais aulas teóricas, porém com atividades em grupo bem como exercícios de cálculos com auxílio de programas em computador. Esse Módulo, como fechamento do Projeto, trouxe ao grupo de jovens o incentivo de buscar capacitação em administrar uma propriedade rural, o que muitos desconheciam.

O Módulo 5 abordou os seguintes assuntos: 
_ Princípios de Administração Rural

_ Introdução a informática

_ Formas de Cooperação na Agricultura

_ Introdução à Agricultura Orgânica e Certificação

_ Sistema Colaborativo de Inclusão Digital e Certificação na Agricultura Familiar

_ Noções Básicas Sobre o Cultivo de Cogumelos Comestíveis

_ Marketing: A Prática de uma Agricultura Sustentável na APA de Botucatu a

partir do Turismo Rural

_ O Jovem Empreendedor Rural

\section{RESULTADOS}

Ao longo dos cinco Módulos oferecidos aos jovens participantes; notou-se preocupação geral em buscar mais informações bem como capacitação para que a permanência no campo se concretize, minimizando assim o fenômeno do êxodo rural.

Após a realização do Módulo1, os participantes buscaram se comunicar com os monitores das frentes de aulas oferecidas; além de repassar as informações adquiridas, aos pais e amigos, sobre alguns temas, tais como o de "Primeiros socorros e Curativos"; pois muitos conceitos foram desmistificados e outros foram apresentados como informações inéditas no cotidiano desses jovens.

O tema sobre "Biologia e Identificação de Animais Peçonhentos e Prevenção Contra Acidentes"; contribuiu para o esclarecimento dos jovens. Ficou claro que não existe nenhum animal nocivo presente na natureza, pois todas as espécies se equilibram; e a importância do conhecimento de características que classificam um animal como peçonhento, contribui para a prevenção de acidentes e também para a utilização de tratamentos eficazes.

Já na frente de aula de "Treinamento e Educação no Setor de Tecnologia de Aplicação de Agrotóxicos"; os jovens perceberam o quanto é importante conhecer bem as tecnologias utilizadas no campo para minimizar o impacto ambiental e também aprenderam que o uso de EPIs é de suma importância para a saúde do agricultor. 
O mesmo se aplicou para frente de aula "Introdução a Ergonomia e Segurança do Trabalho", pois muitos acidentes ocorrem no meio rural e houve relatos durante a aula para discussões.

Em relação à frente de aula "Escravidão Branca: Mito ou Realidade muito próxima a nós? Legislação e Normas: Tópicos em Sustentabilidade" notou-se que 100\% dos alunos não conheciam o assunto e através da aula, os mesmos foram conscientizados desse problema ainda existente no estado de São Paulo, na região da APA de Botucatu, bem como no Brasil. Todos se sensibilizaram e foram motivados a buscar mais informações sobre o assunto para informar seus pais.

Ao abordarmos o assusto "Nutrição: Alimentação Saudável para você e o Meio Ambiente" os alunos demonstraram muito interesse em conhecer melhor os alimentos e assim entender a importância da mudança nos hábitos alimentares.

Os jovens costumam preencher as quantidades calóricas ao dia, mas nem sempre em qualidade e sim em quantidade (com açúcar e gordura) ficando carente de outras substâncias importantes. Assim os monitores trouxeram de forma sábia essa conscientização ao longo das aulas.

Em geral, os alunos conseguiram compreender e assimilar a importância da Nutrição e como esta pode melhorar sua qualidade de vida. A troca de experiência foi muito proveitosa, sendo esta uma das maiores recompensas que o Projeto trouxe para os monitores participantes do curso de Nutrição da UNESP.

"As Plantas Medicinais e a Sustentabilidade da APA de Botucatu" foi abordada de forma brilhante e os alunos apresentaram muito interesse pelo assunto. Ambas as partes, não holisticamente, conscientizaram-se do que é uma essência natural, como utilizá-la, o porquê utilizar, como produzir, retirar do ambiente natural sem causar impacto para o mesmo, deixando assim a mensagem de que os recursos podem ser utilizados, porém de forma racional, para que assim, a geração atual, bem como a futura, possam desfrutar do que a natureza oferece.

No Módulo 2, os alunos retornaram após seis meses de espera para a continuação do projeto e se depararam com a realidade de campo que vivenciam em suas casas ou nas propriedades dos seus parentes ou mesmo onde seus pais trabalham. 
A produção vegetal para eles é realizada com os ensinamentos passados de pais para filhos, ou seja, de geração em geração, tudo é feito da mesma maneira. Durante todas as frentes de aula, os alunos compreenderam que muitos métodos e formas de trabalho no campo são ultrapassados e podem ser substituídos por outros que os mesmos desconhecem. Porém, para todos os monitores ficou claro que a Universidade não trouxe um conhecimento inédito para os jovens, mas com a troca de experiência de ambos os lados, construiu-se um novo saber, pois a vivência no campo é única e é necessário estar lá para conhecer as glórias e as dificuldades.

Dessa maneira, as 40 horas de aulas práticas e teóricas das frentes de aula oferecidas foram realizadas com muito questionamento feito pelos jovens, bem como colocações de experiências pessoais dos mesmos.

Os monitores ficaram impressionados com o interesse e educação dos alunos e todos se demonstraram muito participativos.

No módulo 3, procurou-se mostrar a importância do trabalho com os animais, focando o bem-estar, os sistemas produtivos zootécnicos, pastagens, manejos, dentre tantos outros temas abordados. Muitos dos sistemas produtivos apresentados; os jovens já conheciam e tinham em suas casas. O que surpreendeu a todos os monitores foi o conhecimento de raças de bovinos e suínos, além de cultivares de pastagens.

Com as atividades teóricas, práticas e demonstrativas foi possível interagir de forma positiva com os jovens e trocar informações e experiências, que forneceram elementos para gerar discussões sobre sustentabilidade da produção animal. Inicialmente identificou-se resistência por parte dos alunos, oriunda dos próprios pais e familiares, a novos conhecimentos e a modificar o trabalho em suas propriedades.

Destacando as frentes de aula "Conceitos Básicos sobre Forragicultura e Integração Lavoura-Pecuária-Floresta" e "Bovinocultura de Leite"; após as discussões e realização de todas as atividades, os grupos compreenderam que a modificação das práticas, realizadas em suas propriedades, é necessária. Contudo, relataram que quando retornassem para suas propriedades, enfrentariam a resistência de seus familiares para promover a mudança.

A totalidade dos jovens não considerava o bem-estar animal como fator influente nos resultados desejáveis de produção. Muitos afirmaram nunca ter pensado que o bem- 
estar animal é um componente muito importante no sistema de produção animal e que não conheciam esse termo na pecuária. Também foi observado que $100 \%$ dos jovens não tinham conhecimento sobre formação e manejo, adequados de pastagens, evitando degradação do solo e das pastagens.

Todos os jovens não conheciam o sistema de integração lavoura-pecuária-floresta como proposta para promover recuperação de áreas degradadas, para promover sombreamento aos animais, além de ser uma alternativa sustentável e rentável para 0 produtor rural. Vale ressaltar que essa atividade, como conceito tecnológico é uma atividade tão antiga quanto à domesticação dos animais e das plantas. $O$ interesse por mais informações foi surpreendente e os jovens procuraram mais informações sobre 0 sistema durante a aula demonstrativa.

Ao término da aula demonstrativa na propriedade particular, os jovens interessaram-se em buscar mais capacitações para otimizar suas atividades no campo e, assim, garantir a sobrevivência e qualidade de vida de suas famílias com as atividades agrícolas.

Na frente de aula "Produção de Suínos" os resultados foram semelhantes, porém, demonstrou-se que uma possibilidade de expansão da criação sustentável na região da APA de Botucatu é a reutilização de raças nacionais para fins comerciais, que foram extintas pela introdução de raças especializadas a níveis industriais.

Nas frentes de aula "Ovinocultura de Sustentabilidade", "Conceitos Básicos de Piscicultura" "Apicultura - A Arte de Criar Abelhas", os jovens encontram alternativas de sistemas produtivos que não são expressivos na região da APA de Botucatu.

O último tema citado acima foi recebido com muito entusiasmo pelos jovens. Antes da realização das aulas, foi aplicado um questionário com temas para que os jovens apontassem os que mais interessavam. Dos 23 jovens participantes, apenas $26,1 \%$ gostariam de aprender sobre o tema apicultura. Após todas as atividades de apicultura propostas aos alunos, notou-se que o interesse foi geral pelo assunto.

Ao apresentar aos jovens os produtos oriundos da colméia e a rentabilidade que estes podem proporcionar ao produtor, os monitores conseguiram chamar a atenção de todos para a possibilidade da apicultura ser uma fonte de renda extra, além de ser um sistema sustentável. Tais argumentos motivaram, em geral, a adoção do sistema. 
A frente de aula "Tecnologia do Leite" foi dividida em teórica e prática, essa última com a fabricação de queijo. Durante todo o processo de fabricação de queijo observou-se interesse por parte dos alunos e grande expectativa quando o queijo Minas frescal ficou pronto. Essa prática é comum em suas propriedades.

Já o tema "Os Animais Selvagens e a Propriedade Rural" foi ministrado com metodologia através de aula expositiva, visita a instalações e animais sob responsabilidade do CEMPAS e aula prática de observação ornitológica e coleta e identificação de pegadas.

Em geral, os alunos conseguiram compreender e assimilar a importância da preservação do meio ambiente e dos animais silvestres para o meio rural. Conheceram as várias espécies selvagens que podem ser criadas como alternativa de produção animal.

O Módulo 4 apresentou através dos temas propostos; a importância do conhecimento da região; da utilização de recursos naturais de forma sustentável e alternativas para a colaboração da conservação do meio ambiente.

Os jovens assimilaram de forma brilhante que o homem recorre aos recursos naturais para satisfazer suas necessidades, e que no Ecossistema Planeta-Terra há uma troca constante de recursos naturais entre os seres vivos.

Os monitores enfatizaram que os recursos naturais, após seu uso, podem ser renováveis, isto é, voltarem a ser disponíveis, ou não renováveis, isto é, nunca mais ficarem disponíveis.

Compreenderam também que os resíduos sólidos "lixo" é um dos grandes problemas que ameaçam a vida no Planeta Terra, porque além de poluir o solo, a água e o ar, também atrai animais que veiculam doenças. Ao contrário das tribos primitivas que só produziam o necessário para a sua sobrevivência, o homem sobrevive numa sociedade consumista onde as pessoas têm valor pela quantidade de bens que possuem.

Por fim os monitores enfatizaram a importância de um bom manejo do solo pela visão da agroecologia, onde é sempre necessário haver adubação com matéria orgânica, que veio em última instância do solo, a ele retorna transformando-se em nutriente, o qual é assimilado pelas plantas, completando assim, o ciclo da vida; bem como o que vem a ser a Agroecologia. Esse tema veio como alternativa para a agricultura familiar socialmente justa, economicamente viável e ecologicamente sustentável. 


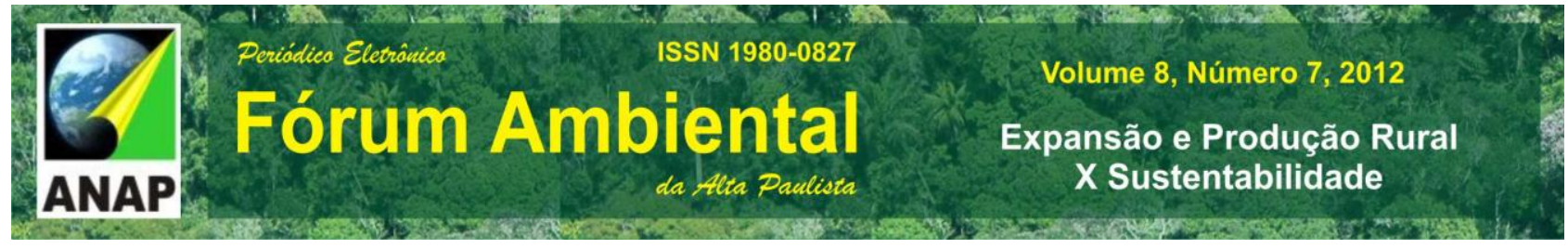

A última etapa do Projeto trouxe através dos temas; como o principal resultado, a capacitação propriamente dita dos estudantes quanto ao aprimoramento da produção agropecuária por meio de processos e instrumentos de planejamento e gestão.

Demonstraram grande interesse na perspectiva econômica, principalmente na interpretação de exercícios práticos de cálculo da rentabilidade que incluía escolhas para a tomada de decisão. Puderam perceber que a unidade produtiva bem administrada tira 0 melhor proveito dos recursos, e obtém lucro em benefício do agricultor e sua família.

Verificou-se que, quase todos tinham pouco conhecimento de administração, e que absorveram com interesse os ensinamentos que lhes foram passados.

Vale ressaltar que os alunos compreenderam que a atividade turística (Turismo Rural, por exemplo), as dadas inegáveis peculiaridades naturais regionais, é uma excelente oportunidade para a sustentabilidade dos agricultores da APA de Botucatu.

Compreenderam que os agricultores devem se valer do Marketing para "profissionalizar" serviços e produtos das propriedades rurais.

A expectativa dos monitores é que as impressões dos alunos sejam repassadas para parentes, familiares, amigos e mesmo autoridades públicas locais.

Após o fechamento do Projeto, a Coordenação teve o privilégio de ser informada que dos 23 jovens participantes; 01 está cursando Agronegócios na FATEC; 02 estão cursando ETC; 02 estão cursando Senai e os demais irão prestar vestibular nos próximos anos para pleitear vagas nos cursos de Agronomia, Administração, Engenharia Florestal e áreas correlatas.

Vale ressaltar que do total de participantes no contato em julho de 2009; apenas 02 queriam cursar o nível superior.

\section{CONCLUSÃO}

O Projeto "Agricultura modelo: Capacitação em agricultura sustentável dos jovens da zona rural da APA de Botucatu" trouxe muito entusiasmo para a Universidade em termos de Extensão. Foi um trabalho desenvolvido com muita dificuldade, pois ainda necessitamos de mais auxílio financeiro, bem como infra-estrutura. Projetos tais como esse, inseridos no Programa Intervivência Universitária são mais que necessários para 
todas as regiões do país, pois cada uma, com suas características, dificuldades e problemáticas estão carentes de assistência de Universidades, pois não basta só pesquisar, mas sim atuar junto à comunidade ao redor com suas descobertas.

Para a Coordenação Geral, ficou o sentimento de dever cumprido, pois o Projeto teve caráter Multidisciplinar, ou o diferenciou de muitos outros projetos de extensão rural. Vale ressaltar que o trabalho desenvolvido com esses jovens teve projeção local; regional e nacional, através da mídia (Jornal, revista e TV); o que prova que exemplos como esse necessitam ser seguidos pois é nítido que dar condições aos filhos dos agricultores familiares (que contribuem de forma expressiva para a economia brasileira dentro do contexto da agropecuária), é possível estimulá-los e viver no campo de forma digna e com qualidade de vida.

\section{REFERÊNCIAS}

Barreto, V. A.V; FONTOURA, L. F. M. O processo de urbanização das cidades locais e a relação cidade-campo: o local e o global a partir de um estudo de caso. Boletim gaúcho de geografia. BGG N. 36 - Porto Alegre - páginas 53-64 - Maio 2011. Disponível em: < http://scholar.google.com.br/scholar?hl=pt-

BR\&q=\%C3\%AAxodo+rural+em+munic\%C3\%ADpios+de+voca $\% C 3 \% A 7 \% C 3 \% A 30+$ agro pecu\%C3\%A1ria\&btnG=\&lr=>. Acesso em: 16 out 2012.

CARNEIRO, M. J. Juventude rural: projetos e valores. In.: ABRAMO, BRANCO, M. D. (Orgs.). Retratos da juventude brasileira: análises de uma pesquisa nacional. São Paulo: Instituto Cidadania/Perseu; Abramo, 2005. 448p.

CHAMPAGNE, P. Elargissement de l'espace social ET crise de l'identité paysanne. Cabiers d'Economie ET Sociologie Rurales n.3. p. 73-89 Dec. 1986.

Kozioski, G. V.; Ciocca, M. L. S. Energia e sustentabilidade em agroecossistemas.

Ciência Rural, Santa Maria, v.30, n. 4, p. 737-745, 2000. 